\title{
The Bacterial Isolates and Plasmid Profile of Extended Spectrum Beta-Lactamases Producers Causing Urinary Tract Infection among Pregnant Women in Uyo, Nigeria
}

\author{
Ifeanyi Abraham Onwuezobe, Florence Effiong Orok \\ Department of Microbiology, University of Uyo, Uyo, Nigeria \\ Email: ifezobe@yahoo.com
}

Received 7 June 2015; accepted 30 June 2015; published 3 July 2015

Copyright (C) 2015 by authors and Scientific Research Publishing Inc. This work is licensed under the Creative Commons Attribution International License (CC BY). http://creativecommons.org/licenses/by/4.0/

(c) (i) Open Access

\section{Abstract}

Background: Extended spectrum beta-lactamases (ESBLs) are enzymes that compromise the efficacy of all beta-lactams and are spread by plasmids. They are of public health importance the world over; however, in Nigeria in general and Uyo in particular, tests for their detection are not routinely done in hospital laboratories despite increase in treatment failures observed for common clinical conditions like urinary tract infection. Objective: To isolate ESBLs producing uropathogens and the plasmid underlying their resistance to antibiotics. Materials and Methods: Three hundred urine specimens $(n=300)$ were collected from pregnant women attending antenatal clinics at St. Lukes Hospital, Anua, cultured and incubated according to accepted standard. Identification of isolates was done using Microbact 24E (Oxoid, UK) system. The predominant bacterial pathogens were Escherichia coli (42\%) followed by Klebsiella pneumonia (21\%), Klebsiella oxytoca (12\%), Citrobacter spp. (5\%), Proteus mirabilis (7\%), Enterobacter spp. (12\%) and Acinetobacter baumanii (1\%). The isolated bacteria were tested for their antibiotic susceptibility using Clinical Laboratory Standard Institute (CLSI) recommended disc diffusion method. A Double Disk Synergy Test (DDST) and Phenotypic Disk Confirmatory Test (PDCT) were performed to determine ESBL production. Chromagar ESBL was also used to test for the presence of ESBL producing isolates. The plasmid content of ESBL producing isolates and their participation in drug resistance were investigated. Results: Of the $\mathbf{8 0}$ bacterial isolates causing urinary tract infection in these women, the ESBL producers were found to be $16(20 \%)$. Out of these 16 ESBL producing urogenital isolates Klebsiella pneumonia (8, 50\%) was the most prevalent. Others include Escherichia coli (38\%), Klebsiella oxytoca (6\%) and Enterobacter cloacae (6). Plasmid content of ESBL producing isolates was found to be $\mathbf{8 7 . 5 \%}$. Conclusion: The Extended Spectrum Beta-lactamase producing uropathogens mainly of plasmid origin are increasingly responsible for the cause of community acquired urinary tract infections in pregnant women in Uyo. 


\section{Keywords}

\section{ESBL, Plasmid Content, Uropathogens}

\section{Introduction}

Urinary tract infection is defined as multi-action of organisms in the urinary tract with the presence of $>10^{5}$ organisms per milliliter in mid-stream urine [1]. The organisms causing UTI in community include Escherichia coli which is the commonest, Proteus spp., Klebsiella spp., Pseudomonas spp. and Streptococci spp. [2].

Pregnant women are at risk of urinary tract infections beginning in week 6 and peaks at weeks 22 to 24 [3]. The three clinical manifestations of UTIs in pregnancy are asymptomatic bacteriuria, acute cystitis and pyelonephritis [4]. Abortion, small birth size, maternal anaemia, hypertension, preterm labour, phlebitis, thrombosis, and chronic pyelonephritis are related to urinary tract infection during pregnancy [5].

Gram negative bacteria have the potential not only to develop chromosomal resistance but also to quickly spread resistance via genetic determinants carried on plasmids or transposons and rapid spread through human travel and migration. These resistant elements have created a global treatment crisis. Multi drugs resistance is increasingly seen in many Gram negative bacteria as a result of wide spread use of various antibiotics [6].

Extended spectrum Beta-lactamases (ESBls) are enzymes that compromise the efficacy of all beta-lactams, except Cephamycins and Carbapenems by hydrolysis of beta-lactam ring and are inhibited by beta-lactam inhibitors [7]. Resistant bacteria are a big threat to hospitals and community [7]. Among the wide array of antibiotics, beta-lactams are the most commonly used agents accounting for over $50 \%$ antibiotics in use [7]. There are various types of ESBLs derived mainly from the groups TEM, SHV, and CTX-M variants. This extended-spectrum $\beta$-lactamases contribute to multidrug resistance among the organisms and detection of these enzymes is crucial to treatment. Their detection is therefore significant in preventing treatment failures caused by these pathogens.

Plasmids are linear but usually circular replicons of extra chromosomal DNA in bacteria, and they play an important role in the evolution of microbes [8]. The genes encoding ESBLs are usually located on plasmids that are highly mobile and can harbor resistance genes to several other unrelated classes of antimicrobials [9], such as the plasmid-mediated quinolone resistance gene and aminoglycoside resistance gene [10].

\section{Methodology}

Bacterial isolation: All urine samples (first morning urine) were aseptically inoculated unto MacConkey and blood agars using the calibrated loop technique. After overnight incubation at $37^{\circ} \mathrm{C}$ for 24 hours, colony counts yielding bacterial growth of $10^{5} / \mathrm{ml}$ of urine were regarded as significant for bacteriuria. Identification of bacterial isolates was carried out using Microbact 24E (MB24E).

ESBL detection: For the Phenotypic Disk Confirmatory Test (PDCT), all isolates showing inhibition zone size of $\leq 22 \mathrm{~mm}$ with ceftazidime $(30 \mu \mathrm{g}), \leq 25 \mathrm{~mm}$ with cefotazime $(30 \mu \mathrm{g}), \leq 27 \mathrm{~mm}$ with Azetronam $(30 \mu \mathrm{g})$ and $\leq 22 \mathrm{~mm}$ with cefpodoxime $(10 \mu \mathrm{g})$ was identified as potential ESBL. A Double Disk Synergy Test (DDST) was done in which case, Ceftazidime $30 \mu \mathrm{g}$ disc was placed on Mueller Hinton sensitivity plate $20 \mathrm{~mm}$ (center to center) from Augumentin $30 \mu \mathrm{g}$ disk (amoxicillin and clavulanate $20 \mu \mathrm{g} / 10 \mu \mathrm{g}$ ). After incubation for $18-24$ hours at $37^{\circ} \mathrm{C}$ a clear extension of the edge of ceftazidime disc inhibition zone towards the disk containing clavulanate is described as synergy indicating the presence of an ESBL. Furthermore, gram negative bacterial isolates were cultured on Chromagar which is a chromogenic medium designed specifically for the Screening of Extended Spectrum $\beta$-Lactamase-producing Enterobacteria (ESBL) [11]. The antibiotic discs were from OXIOD England, and the various methods of ESBL detection used were for comparison and quality control. Plasmid DNA Isolation and Gel electrophoresis: Subculture was done on Tryptone Soya Agar and a horizontal electrophoresis apparatus were applied following standard procedures for the isolation of plasmid DNA and electrophoresis respectively [12]. The data obtained were analysed statistically using the chi square to determine the relationship between the variables and its significance. 


\section{Results}

The 300 urine samples from different age groups of pregnant women (Table 1), yielded 80 clinical isolates including Escherichia coli (42\%) followed by Klebsiella pneumoniae (21\%), Klebsiella oxytoca (12\%) Citrobacter spp. (5\%), Proteus mirabilis (7\%), Enterobacter spp. (12\%) and Acinetobacter baumanii (1\%) were obtained (Table 2).

The isolates were screened for ESBL production and 16 (20\%) were found to be ESBL producers by the DDST method viz; Klebsiella spp. (56\%), Escherichia coli (38\%), and Enterobacter cloacae (6\%) as shown in Table 3. The PDCT and the Chrom agar ESBL test methods revealed more numbers of ESBL producers at $47 \%$ and 70\% respectively (Table 3). Some strains of Klebsiella pneumoniae especially K. pneumoniae-3 and 5 were not of plasmid origin (Table 4). The Agarose gel electrophoresis of plasmids recovered from the ESBL isolates is as shown in Figure 1.

Table 1. Distribution of bacterial isolates among the pregnant women.

\begin{tabular}{ccc}
\hline Age group (yrs) & No. of samples (\%) & Number of isolates (\%) \\
\hline $15-24$ & $100(33.3)$ & $27(33.7)$ \\
$25-34$ & $157(52.3)$ & $45(56.3)$ \\
$35-44$ & $43(14.3)$ & $8(10.0)$ \\
Total & $\mathbf{3 0 0 ( 1 0 0 )}$ & $\mathbf{8 0}(\mathbf{1 0 0})$ \\
\hline
\end{tabular}

Table 2. Frequency of bacterial isolates.

\begin{tabular}{cc}
\hline Bacterial isolates & Total No. (\%) \\
Eschericha coli & $32(40)$ \\
Klebsiella pneumonia & $16(20)$ \\
Klebsiella oxytoca & $9(11)$ \\
Citrobacter sakazakii & $2(3)$ \\
Citrobacter freundii & $2(2)$ \\
Proteus mirabilis & $1(1)$ \\
Enterobacter spp. & $11(14)$ \\
Acinetobacter baumanii & $7(9)$ \\
Total & $\mathbf{8 0}(\mathbf{1 0 0})$ \\
\hline
\end{tabular}

Table 3. ESBLs detection by PDCT, DDST and Chrom agar ESBL.

\begin{tabular}{|c|c|c|c|c|}
\hline Bacterial isolates & Total n (\%) & PDCT n (\%) & DDST n (\%) & Chrom Agar ESBL n (\%) \\
\hline E. coli & $32(40)$ & $19(40)$ & $6(38)$ & $32(46)$ \\
\hline Klebsiella spp. & $25(32)$ & $13(28)$ & $9(56)$ & $25(35)$ \\
\hline Citrobacter spp. & $4(5)$ & $1(2)$ & $0(0)$ & $4(6)$ \\
\hline P. mirabilis & $1(1)$ & $1(2)$ & $0(0)$ & $0(0)$ \\
\hline E. cloacae & $11(14)$ & 7 (15) & $1(6)$ & $9(13)$ \\
\hline A. baumanii & 7 (9) & $6(13)$ & $0(0)$ & $0(0)$ \\
\hline Total & 80 (100) & $47(100)$ & $16(100)$ & $70(100)$ \\
\hline
\end{tabular}

Chi square test, the level of statistical significance was $p<0.05$. Key: DDST: Double Disk Synergy Test, PDCT: Phenotypic Disc Confirmatory Test. 


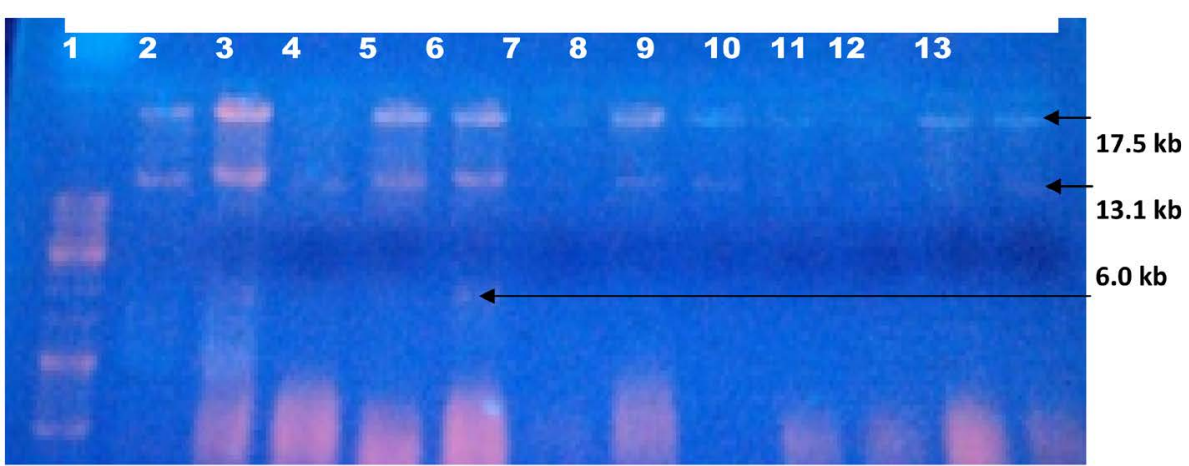

Figure 1. Agarose gel electrophoresis of plasmids recovered from the ESBL isolates. Lane 1. $10 \mathrm{~kb}$ DNA ladder; Lanes 2-8 = K. pneumoniae 02-08; Lanes 9 = Enterobacter cloacae 01; Lanes $10-13=$ E. coli 02 .

Table 4. Plasmid profiles of ESBL producing isolates.

\begin{tabular}{cc}
\hline Bacterial Isolates & Plasmid size, kb \\
\hline K. Oxytoca & $17.5,13.5$ \\
E. coli-1 & 17.513 .5 \\
E.coli-2 & $17.5,13.5,8.0,6.0$ \\
E.coli-3 & $17.5,13.5$ \\
E. coli-5 & $17.5,13.5$ \\
E. coli-6 & $17.5,13.5$ \\
K. Pneumoniae-1 & $17.5,13.5,8.0$ \\
K. Pneumoniae-2 & $17.5,13.5$ \\
K. Pneumoniae-3 & - \\
K. Pneumoniae-4 & $17.5,13.5$ \\
K. Pneumoniae-5 & - \\
K. Pneumoniae- 6 & $17.5,13.5$ \\
K. Pneumoniae-7 & $17.5,13.5$ \\
K. Pneumoniae-8 & $17.5,13.5$ \\
K. Pneumoniae-9 & $17.5,13.5$ \\
E. cloacae & $17.5,13.5$ \\
\hline
\end{tabular}

\section{Discussion}

This study revealed 80 positive cultures out of the 300 urine samples or $26.6 \%$ prevalence rate of Gram negative bacteria isolates as a cause of Urinary tract infection (UTI) in pregnancy in Uyo. Although Escherichia coli was found to be the most common cause, studies from some Cities in Nigeria and other African countries has reported higher rates of urinary Gram negative bacterial isolates of up to $51.0 \%, 67.5 \%$ and $61.9 \%$ in Rivers state Nigeria, Ethopia and Tanzania respectively [13]-[15]. The lower percentage could be attributed to standard sample collection and automated biochemical method of bacterial identification employed in this study as against the conventional method of bacterial identification used in these other studies. Of note also is the higher rate of urinary tract infection 45 (56.3\%) among women of age bracket 25 - 34 years. This may be attributed to the fact that most women at this age are likely to have gotten married and would want to have children as revealed by their more participation in this study.

Extended-spectrum beta lactamase producing uropathogens are of public health concern because of their ability to express resistance to antibiotics used in treating urinary tract infections. In this study, the commonly used DDST method of assessing ESBL showed a total prevalence of $20 \%$. This agrees with some studies which showed prevalences between 22\% and 27.7\% [16]-[19]. However, other methods used in this study (PDCT and Chrom agar) used for the detection ESBL revealed higher overall and individual isolates prevalences. This may be due to the higher sensitivities of these methods in detecting ESBL. Some recent studies reported significantly 
higher prevalence of ESBL UTI [20] reported a prevalence of 59.6\% respectively.

Fourteen out of the 16 ESBL producing isolates harboured plasmids; 2 isolates did not contain plasmid. This could be due to the fact that many of the genera of gram negative bacteria possess a naturally occurring chromosomally mediated beta-lactamases [9]. This result agrees with the findings of [21]. The involvement of plasmids as a factor responsible for antibiotic resistance in the ESBL isolates further suggests the emergence and active transfer of antibiotic resistance and R plasmids among the circulating strains causing ESBL UTI in Uyo.

\section{Conclusion}

The extended spectrum beta-lactamases producing uropathogens mostly of plasmid content are responsible for community acquired urinary tract infection among pregnant women in Uyo. The detection for ESBL is not routinely requested or tested. It is therefore important to change this practice to prevent the treatment failures caused by these pathogens.

\section{References}

[1] Giraldo, P.C., Araujo, E., Junior, R., Amaral, R., Passos, M. and Goncalves, A. (2012) The Prevalence of Urogenital Infections in Pregnant Women Experiencing Pretem and Full Term Labour. Infectious Diseases in Obstetrics and Gynecology, 2, 878.

[2] Guerra, G., Costa, B.F., Nascimento, F., Amaral, M. and Serafim, A. (2012) Urine Test to Diagnose Urinary Tract Infection in High-Risk Pregnancy Women. Revista Brasileira de Ginecologia e Obstetrícia, 34, 488-493. http://dx.doi.org/10.1590/S0100-72032012001100002

[3] John, E.D. and Michael, L.L. (2000) Urinary Tract Infections during Pregnancy. American Family Physician, 61, 713721.

[4] Loh, K.Y. and Silvalingam, N. (2007) Urinary Tract Infections in Pregnancy. Malaysian Family Physician, 2, 54-57.

[5] Onuh, S.O., Umeora, O.U.J., Igberase, G., Azikem, M.E. and Okpere, E.E. (2006) Microbiological Isolates and Sensitivity Pattern of Urinary Tract Infection in Pregnancy in Benin City, Nigeria. Ebonyi Medical Journal, 5, 48-52.

[6] Livermore, D.M. (2003) Bacterial Resistance: Origins, Epidemiology and Impact. Clinical Infectious Diseases, 36, 1123. http://dx.doi.org/10.1086/344654

[7] Coque, T.M., Baquero, F. and Canton, R. (2008) Increasing Prevalence of ESBL. Eurosurveillance, 13, 347-349.

[8] Johnson, T.J. and Nolan, L.K. (2009) Plasmid Replicon Typing. Methods of Molecular Biology, 51, 27-35. http://dx.doi.org/10.1007/978-1-60327-999-4 3

[9] Bradford, P.A. (2001) Extended-Spectrum Beta-Lactamases in the 21st Century: Antimicrobial Agents and Chemotherapy, 32, 2227-2238.

[10] Rodriguez, B.J., Alcala, J.C. and Cisneros, J.M. (2009) Community Infections Caused by Extended Spectrum BetaLactamases Producing Escheria coli. Archives of Internal Medicine, 168, 1897-1902. http://dx.doi.org/10.1001/archinte.168.17.1897

[11] Glupczynski, Y., Berhin, C., Bauraing, C. and Bogaerts, P. (2007) Evaluation of a New Selective Chromogenic Agar Medium for Detection of Extended-Spectrum $\beta$-Lactamase-Producing Enterobacteriaceae. Journal of Clinical Microbiology, 45, 501-505. http://dx.doi.org/10.1128/JCM.02221-06

[12] Meyers, J.A., Sanchez, D., Elwell, L.P. and Falkow, S. (1976) Simple Agarose Gel Electrophoretic Method for the Identification and Characterization of Plasmid Deoxyribonucleic Acid. Journal of Bacteriology, 20, 1529-1537.

[13] Aiyegoro, O.A., Igbinosa, O.O., Ogunmwonyi, I.N., Odjadjare, E.E., Igbinosa, O.E. and Okoh, A.I. (2007) Incidence of Urinary Tract Infections among Children and Adolescents in Ille-Ife, Nigeria. African Journal of Microbiology Research, 15, 13-19.

[14] Pondei, K., Langley, O. and Pondei, J. (2012) Current Microbial and Culture Sensitivity Pattern of Urinary Tract Infection in a Private Setting in Bayelsa State, Nigeria. International Research Journal of Microbiology, 3, 393-398.

[15] Alemu, A.T., Moges, S.W., Shiferaw, S.T., Tafess, S.T., Kassu, T.S., Anagaw, S.V. and Agegn, G.S. (2012) Recent Development in the Diagnosis and Treatment of Urinary Tract Infections. Nigeria British Journal of Obstetrics and Gynaecology, 11, 23-30.

[16] Agarawal, P., Ghosh, A.N., Kumar, S., Basl, B. and Rapila, K. (2008) Prevalence of Extended-Spectrum $\beta$-Lactamases among E. coli and Klebsiella pneumonia Isolates in Tertiary Care Hospital. Indian Journal of Pathology and Microbiology, 13, 139-142. http://dx.doi.org/10.4103/0377-4929.40428

[17] Ejikuegwu, P.C., Ikegbunam, N.M., Ugwu, C.M., Iroha, I.R. and Esimone, C.O. (2012) Extended-Spectrum $\beta$-Lactamase 
Producing E. coli Isolatesfrom Suspected Community Acquired Urinary Tract Infections. European Journal of Scientific Research, 84, 565-571.

[18] Ramazanz, R. (2010) Etiologic Agents and Extended-Spectrum $\beta$-Lactamase Production in Urinary Tract Infections in Sanandaj, Iran. Eastern Journal of Medicine, 15, 57-62.

[19] Mumtaz, S., Ahmad, M., Aftab, I., Akhtar, N., ul Hassan, M. and Hamid, A. (2007) Extended Spectrum $\beta$-Lactamases in Enteric Gram-Negative Bacilli: Related to Age and Gender. Journal of Ayub Medical College Abbottabad, 19, 107111.

[20] Omar, B., Aifadel, O.O., Atif, H.A. and Mogahid, M. (2013) Increasing Prevalence of ESBL Producing Enterobacteriaceae. Life Science Journal, 13, 556-559.

[21] Marhova, K., Kostadinova, T. and Stoitos, M. (2009) ESBL: An Increasing Threat. Antimicrobial Agent and Chemotherapy, 15, 375-379. 